\title{
Editorial
}

\section{Health financing seen from the global level: beyond the use of gross national income}

\author{
MARK DYBUL* \\ The Global Fund to Fight AIDS, Tuberculosis and Malaria, Geneva, Switzerland
}

For several decades, International development and financing institutions have considered gross national income (GNI) the economic touchstone for assessing and evaluating countries' eligibility for development assistance. The World Bank first developed the metric in 1960s as the basis for decisions on concessional financing through International Development Association (IDA). Since its establishment, the IDA has approved concessional financing worth around $\$ 312$ bn to low-income countries (LICs), a term referring to economies below a certain GNI per capita threshold. ${ }^{1}$

The critical comparative advantage of GNI as a metric is its simplicity: it is a standardised statistic that is annually estimated for most economies and captures the level of wealth generated in that year. Historically, this aggregate level of wealth has been considered a useful proxy for the level of development. As a result, this universal, simple, standardised indicator, has been adopted to guide decision making in other financing institutions, ${ }^{2}$ but also more broadly, in global health. Key multilateral health financers and development agencies that disburse about $75 \%$ (Global and Donor Financing, 2012) of available external financing for health, base their eligibility, allocation and co-financing policies on GNI per capita levels [Equitable Access Initiative (EAI), 2016].

\section{Changing landscape: poverty, disease burden and middle-income economies}

In the last decade, globalisation-driven rapid economic growth and statistical revisions have resulted in unprecedented movement of countries upwards across

\footnotetext{
"Correspondence to: Mark Dybul, The Global Fund to Fight AIDS, Tuberculosis and Malaria, Chemin de Blandonnet 8, 1214 Vernier, Geneva, Switzerland. Email: mark.dybul@theglobalfund.org

1 The low-, middle- and high-income group thresholds were established in 1989 based largely on operational thresholds that had previously been established. These thresholds are updated annually at the beginning of the World Bank's fiscal year (i.e., 1 July), with an adjustment for inflation.

2 Including the Asian Development Bank, the African Development Bank and the Inter-American Development Bank.
} 
these income groups, posing a critical question of whether GNI remains a useful proxy of development and health needs. Of the 63 economies classified as LICs in 2000 , only 34 remain in this category today, representing less than $11 \%$ of the global population (Alonso et al., 2015). Analyses on the issue suggest that within the next 15 years only 16 economies - mostly fragile states and small-island nations - are likely to be in the 'low-income' group that is eligible for IDA financing (Glennie, 2011; Sumner, 2012). ${ }^{3}$ Underlining the immediacy of the situation, a World Bank input into the Sustainable Development Goal (SDG) discussions highlights the possibility that between 2015 and 2017 alone, 25 economies as likely to transition to higher lending groups (The World Bank Group, 2013).

This raises issues for global health, as the largest share of disease burden is now concentrated in middle-income countries (MICs) rather than LICs, a reality that GNI per capita metric was never designed to capture. GNI is an imperfect proxy for health and social development, as it does not reflect inequalities between subnational regions of states nor inequalities among populations within countries. Some of these key populations, for example, transgender people, refugees and prisoners, face high risk and vulnerability to HIV, tuberculosis and malaria, and must be included in the global response to these three diseases.

Presently, $70 \%$ of morbidity and mortality caused by communicable diseases occurs in MICs. ${ }^{4}$ Multilateral global health financers, who were set up with the goal of ending preventable deaths from major infectious diseases, will be challenged to maintain their focus on countries with the least economic capacity while adapting their funding and processes to address this shift in disease burden towards MICs. This will be complicated because most health financing is not provided by health agencies, but by the development finance arms of major donors where GNI is more commonly used than health metrics for allocating funds. Successfully addressing these changes will be critical to continue the fight against infectious disease.

This transition of countries to higher rate lending groups on being classified as middle income is also of general concern to development financers since this process can coincide with the potential loss of financial and technical support from multilateral and bilateral partners. There is concern that some newly MICs with high poverty and disease rates may face rapid declines in official development assistance upon becoming ineligible for grant financing from major development finance institutions (EU Development Policy, 2011).

Further, there is the realisation that rapid economic growth has had lesser than anticipated impact in reducing inequity, with new MICs continuing to house a significant majority of the world's poor. Since 1990, as more countries enter

3 In total, 36 countries will become ineligible for World Bank's IDA financing by 2030, of which 25 economies as likely to transition to higher lending groups between 2015 and 2017 alone.

4 Global Burden of disease 2015 (age and time discounted) (http://ghdx.healthdata.org/gbdresults-tool). 
middle-income status without the wealth generation having benefitted the worst off, the percentage of the world's poor living in MICs has grown from 10 to $70 \%$ (Glassman, 2013; McMichael, 2016). To highlight the severity of the situation, it is estimated that about $60 \%$ of the world's poor live in just five populous newly MICs. ${ }^{5}$

\section{EAI}

In response to these challenge, the EAI was convened in early 2015 by nine leading multilateral health and development organisations to explore the strengths and weaknesses of GNI, and the potential for developing alternative and complimentary measures that could inform policies. Under the able chairmanship of Pascal Lamy ${ }^{6}$ and Donald Kaberuka, and in consultation with leading experts, national governments and civil society, four leading academic groups were tasked with proposing alternatives for the Expert Panel's consideration, based on convergences in their findings.

The analyses identified significant limitations of policy making based on the single GNI variable, but also noted the continued utility of a widely collected and standardised measure of wealth. The EAI concluded that complex health financing polices, including eligibility and prioritisation of health investments, should be informed by a more comprehensive framework for decision making based on the analysis of countries' needs, fiscal capacity and policies. For the Global Fund, this means considering both disease burden data for HIV, tuberculosis and malaria, and measures of economic capacity when allocating funding, while also accounting for unmet needs of key and vulnerable populations.

A second key finding was to emphasise incentive structures when providing grant financing. Several large MICs are far below needed levels of government spending on health, despite having fiscal space to increase social spending. To this end, the analyses highlighted the limitation of GNI per capita as not capturing the current level or future capability of governments to domestically finance health challenges. External financers need to have an explicit focus on domestic government spending on the social sector. For the Global Fund, this means explicit co-financing requirements based on government spending on health that support the sustainability of health programs, but generating increased domestic financing is essential for achieving all of the Sustainable Development Goals.

Finally, the Expert Panel and conveners together recognised the real need to mitigate the risk of disease resurgence when external financing decreases. The initiative recognised the responsibility of external financers, countries and

5 There are, however, clear differences in poverty rates between LICs and MICs: for instance, extreme poverty incidence rates in LICs are extremely high as a whole (about 47\% in 2012) compared with lower middle-income countries (around 18\%) and upper middle-income countries (around 5\%).

6 Former head of the World Trade Organisation; former head of the African Development Bank. 
partners to work together to plan smooth transitions from external financing that enable not only the preservation of the health gains of the past, but the acceleration of progress.

The health and development landscape has shifted and increased in complexity since the beginning of the Millenium Development Goals. As we begin efforts to achieve the SDGs, we must continue to challenge ourselves to adapt our investments, metrics and thinking to this new landscape or risk losing impact.

\section{References}

Alonso, J. A., A. L. Cortez and S. Klasen (2015), 'LDC and Other Country Groupings: How Useful are Current Approaches to Classify Countries in a More Heterogeneous Developing World?', in J. A. Alonso and J. A. Ocampo (eds), Global Governance and Rules for the Post-2015 Era: Addressing Emerging Issues in the Global Environment, 424.

Brenzel, 1. (2012), 'Hospital Pharmacy Management', MDS-3: Managing Access to Medicines and Health Technologies, 3rd ed. WHO Publication, 1088pp [1 December 2016].

EU Development Policy (2011), The Role of Aid to Middle-Income Countries: A Contribution to Evolving EU Development Policy, London: ODI.

Equitable Access Initiative (EAI) (2016), 'Final Draft Report', http://www.theglobalfund.org/ en/equitableaccessinitiative/ [1 December 2016].

Glassman, A., D. Duran and A. Sumner (2013), 'Global health and the new bottom billion: what do shifts in global poverty and disease burden mean for donor agencies?', Global Policy, 4(1): 1-14.

Glennie, J. (2011), The Role of Aid to Middle-Income Countries: A Contribution to Evolving EU Development Policy, London: Overseas Development Institute.

McMichael, P. (2016), Development and Social Change: A Global Perspective. Sage Publications.

Sumner, A. (2012), 'From Deprivation to Distribution: Is Global Poverty Becoming A Matter of National Inequality?', IDS Working Paper, Brighton: IDS.

World Bank Group (2013), 'Financing for Development Post-2015', https://openknowledge. worldbank.org/handle/10986/16310 License: CC BY 3.0 IGO. Washington, D.C. (C) World Bank. 